\title{
Mapping Global Population Exposure to Heatwaves
}

\author{
Qinmei Han, Wei Xu, and Peijun Shi
}

\section{Background}

Global warming has become a severe problem worldwide, where the average global temperature has steadily increased over recent decades, accompanied by the abnormally hot weather (IPCC 2013). Since the 1950s, heatwave events have increased in frequency, intensity, and duration and their impact on human health will also increase under enhanced global warming (Perkins-Kirkpatrick and Lewis 2020). Heatwaves have become one of the most serious climate events in the world. Thousands of people have died from exposing to heatwaves in recent years, for instance, the European heatwave of 2003 induced more than 70,000 additional deaths (Robine et al. 2008). Heat-related mortality and morbidity are not only attributed to natural hazards resulting from climate change (Seneviratne et al. 2012). Both climatic factors and socioeconomic factors such as population change and vulnerability of people exposed to heatwaves have impact on the number of deaths caused by heatwaves. Thus, a comprehensive and quantitative assessment of heatwave exposure is conducive to taking targeted measures to reduce the risk in hotspot regions of the world.

Compared to heat-related mortality risk assessment, assessment of exposure has received little attention in recent years. A few studies have examined global or regional

Authors: Qinmei Han, Wei Xu, Peijun Shi.

Map Designers: Yuanyuan Jing, Jing'ai Wang, Ying Wang. Language Editor: Wei Xu.

Q. Han $\cdot$ W. Xu $\cdot$ P. Shi $(\bowtie)$

Faculty of Geographical Science, Beijing Normal University,

Beijing, 100875, China

e-mail: spj@bnu.edu.cn

W. Xu $\cdot$ P. Shi

State Key Laboratory of Earth Surface Processes and Resource

Ecology, Beijing Normal University, Beijing, 100875, China population exposure to heatwaves (Jones et al. 2015; Liu et al. 2017; Chen et al. 2020), and all the existing results show that heatwave exposure will have a significant increase in the future compared to the historical periods.

We combined the future projections of temperature under the three Representative Concentration Pathways (RCP2.6, RCP4.5, and RCP8.5) and the future projections of population under the three Shared Socioeconomic Pathways (SSP1, SPP2, and SSP3) to evaluate future population exposure to heatwaves across the world at the grid level $\left(0.25^{\circ} \times 0.25^{\circ}\right)$ and the country level, respectively, in different time periods. The scenario combinations are RCP2.6-SSP1, RCP4.5-SSP2, and RCP8.5-SSP3. We also computed the decadal exposure change in the 2030s (20162035) and the 2050s (2046-2065) compared to the baseline period (1986-2005) using high spatial resolution climate and population data under different scenario combinations.

\section{Method}

This study used daily maximum temperature as metric to estimate heatwaves. The daily maximum temperature data were obtained from the NASA Earth Exchange Global Daily Downscaled Projections (NEX-GDDP), which was released in June 2015 (https://dataserver.nccs.nasa.gov/thredds/ catalog/bypass/NEX-GDDP/catalog.html). The spatial resolution of the data is $0.25^{\circ} \times 0.25^{\circ}$. There are 21 general circulation models in this dataset, which contain two Representative Concentration Pathways (RCPs) - RCP4.5 and RCP8.5-for the period from 1950 to 2100. The temperature data of the lower emissions scenario RCP2.6 was computed by sub-project 1 . The population projection data used in this study contained SSP1-3 computed by sub-project 2. We calculated heatwave intensity and heatwave exposure for two time periods (2016-2035 and 2046-2065) in the future 


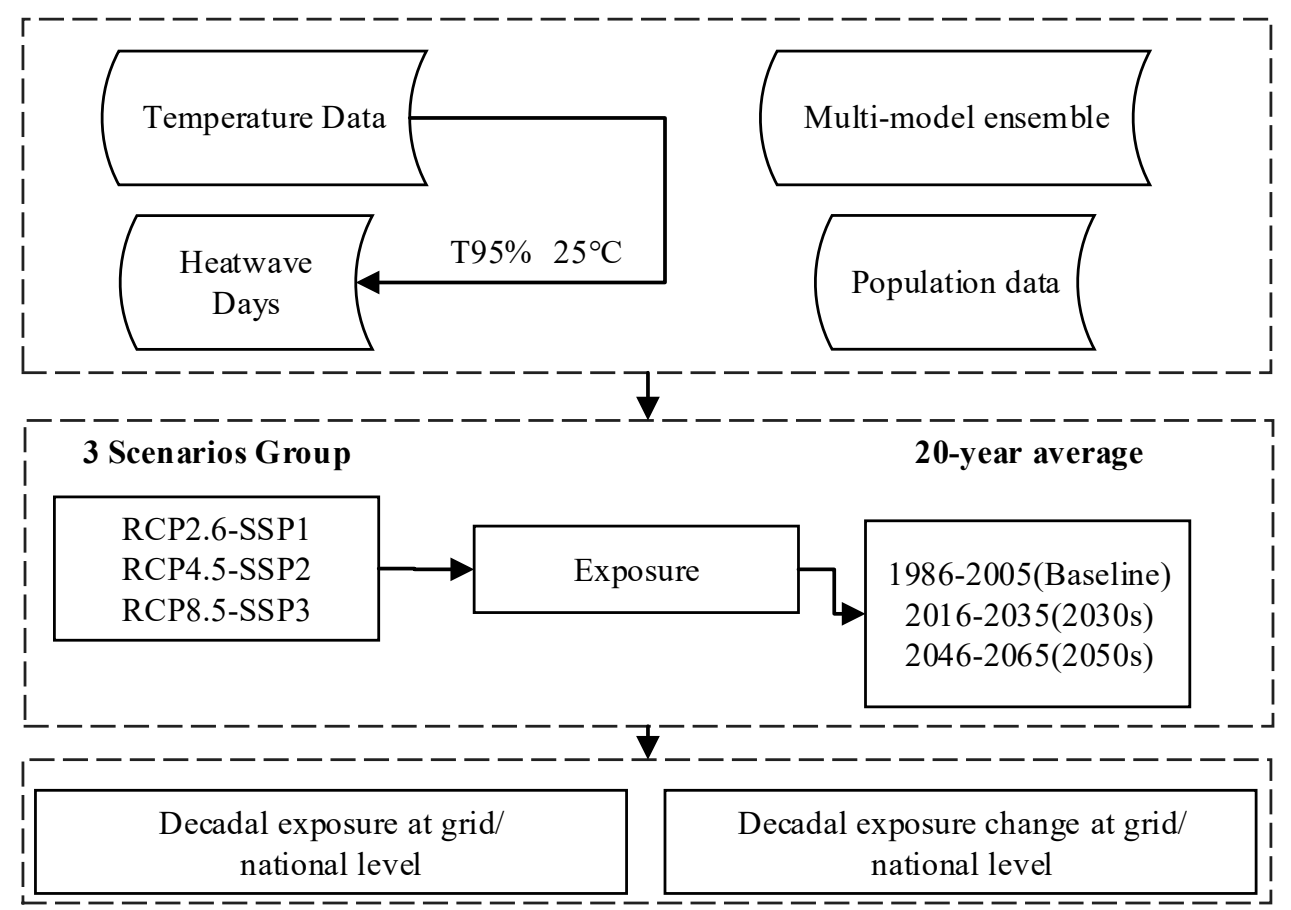

Fig. 1 Technical flowchart for mapping global heatwave exposure

compared to 1986-2005 under the three RCP-SSPs combinations-RCP2.6-SSP1, RCP4.5-SSP2, and RCP8.5-SSP3. Figure 1 shows the technical flowchart for mapping the global population exposure to heatwaves.

\subsection{Heatwave Intensity Metrics}

Heatwave was defined here as at least 3 consecutive days exceeding the given temperature threshold, which is the 95th percentile value of the daily maximum temperature series over the baseline period 1986-2005 at the grid level, and if the 95th percentile value was lower than $25^{\circ} \mathrm{C}$, we set $25^{\circ} \mathrm{C}$ as the threshold in this grid. The annual heatwave intensity was quantified as the total heatwave days in a year.

\subsection{Exposure}

In this study, exposure was defined as the total population exposed to a heatwave, which was calculated by multiplying annual population and annual total number of heatwave days at the grid level. So the unit of exposure is person-day. For both the baseline period (1986-2005) and the future periods
(2016-2035, 2046-2065), we calculated the 20-year average value of exposure to map the global exposure to heatwaves and compute the interdecadal change of exposure. In addition, we aggregated exposure of the grid level to the national level for further analysis.

\section{Results}

\subsection{Heatwave Intensity}

The spatial patterns of multi-model ensemble heatwave days for both the baseline period and the future periods are similar, whereas the regions with high heatwave days are mainly distributed at the equator and gradually decrease with increasing latitude. The number of heatwave days significantly increases over time. The global mean annual heatwave days in the baseline period are 18 days, which increase up to 50 days in the 2050s under high-emission scenarios. The highest heatwave days are 50.7 days in the baseline period, which is estimated to exceed 300 days in the 2050 s under the RCP8.5 scenarios. The heatwave days are significantly higher in the 2050s (2046-2065) than the 2030s (2016-2035) under different scenario combinations. 


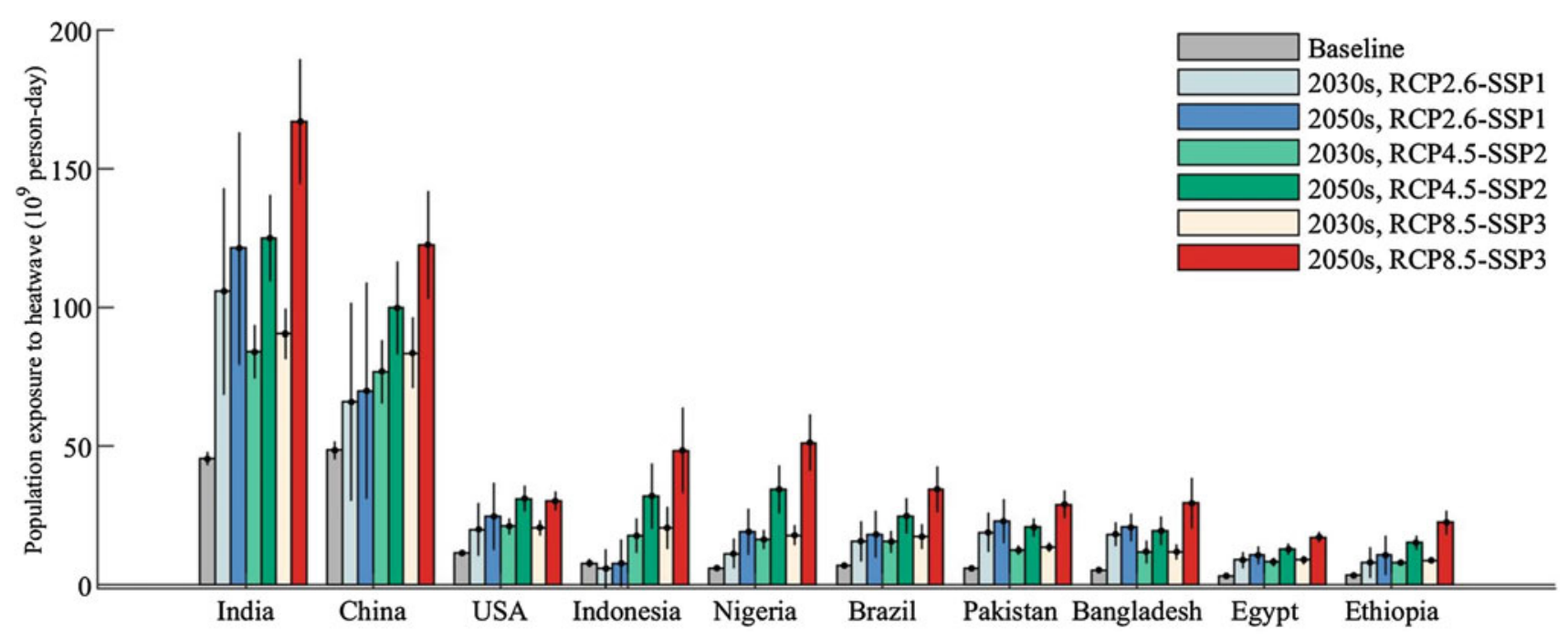

Fig. 2 Population exposure to heatwaves of the top 10 countries. The error bar represents the one standard deviation across the 21 (13 for Representative Concentration Pathway(RCP)2.6) general circulation models and 3 shared socioeconomic pathways (SSPs)

\subsection{Heatwave Exposure}

Regions with high heatwave exposure are primarily concentrated in densely populated areas, such as India, China, central Europe, and eastern United States for both the baseline and the future periods. It is estimated that in the 2050s (2046-2065), under the high-emission scenario (RCP8.5-SSP3), the global 20-year average exposure to heatwaves will increase by 3.4 times $(\sim 103.1$ billion person-day) compared to the baseline period ( $\sim 24$ billion person-day), including 6.8 times in Africa, 4.8 times in South America, 2.7 times in Asia, 2.7 times in North America, 1.3 times in Europe, and 2.6 times in Oceania. Under the low-emission scenarios RCP4.5-SSP2 and
RCP2.6-SSP1, the global average heatwave exposure increases by 2.2 times ( $\sim 75.7$ billion person-day) and 1.4 times ( $\sim 56.0$ billion person-day), respectively.

Exposure to heatwaves at the grid level was aggregated to the country scale for further analysis. The top 10 countries with high heatwave exposure are shown in Fig. 2. These countries are mainly located in Africa and Asia. Compared to the baseline period, the heatwave exposure of all countries increased significantly especially in the 2050s under different scenario combinations. For example, the annual total heatwave exposure of India is about 4.5 billon person-day in the historical period (1986-2005), which increases to 16.7 billion person-days for 2046-2065 under the RCP8.5-SSP3 scenario. 


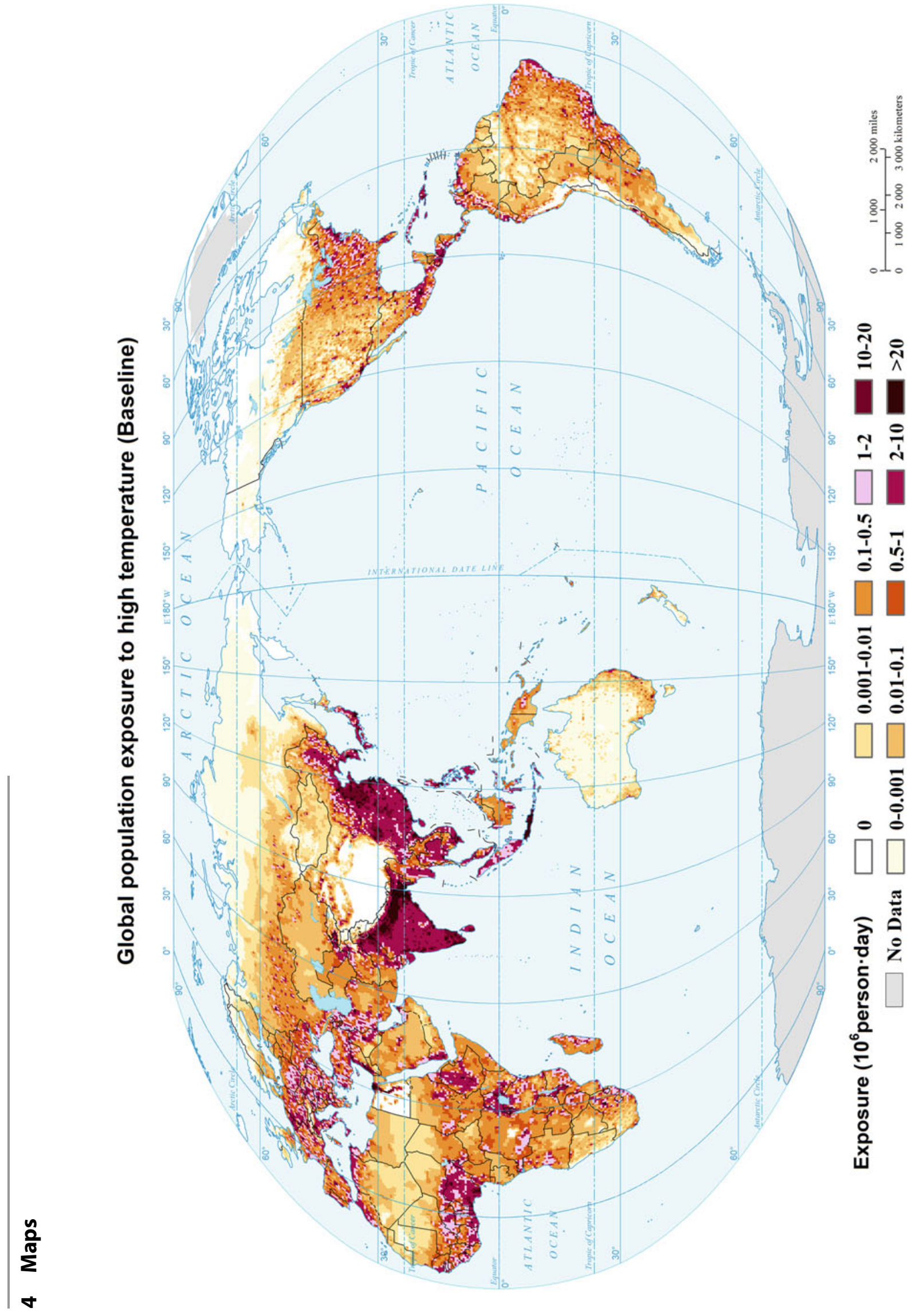


Global population exposure to high temperature (2030s, RCP2.6-SSP1)

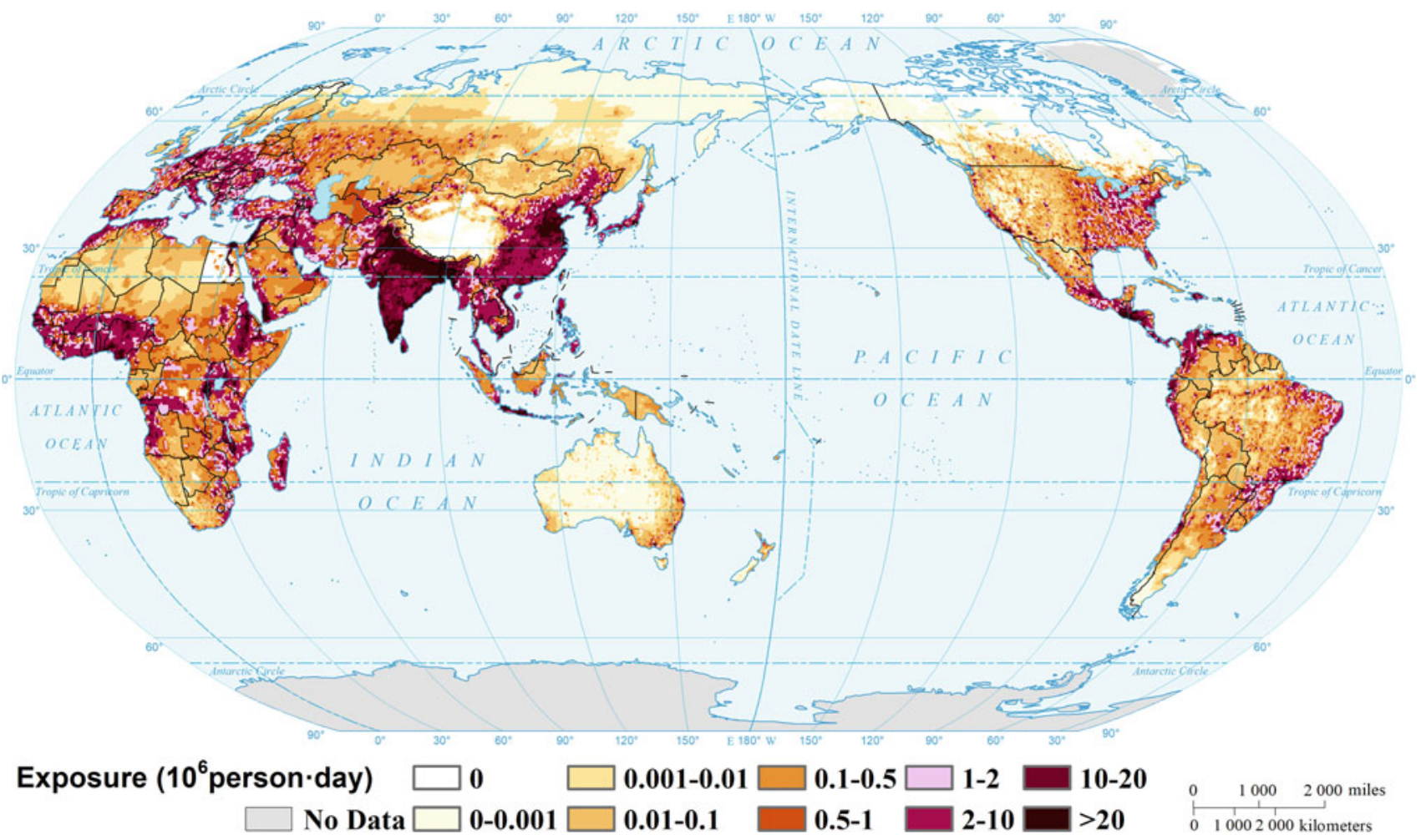

Global population exposure to high temperature (2030s, RCP4.5-SSP2)

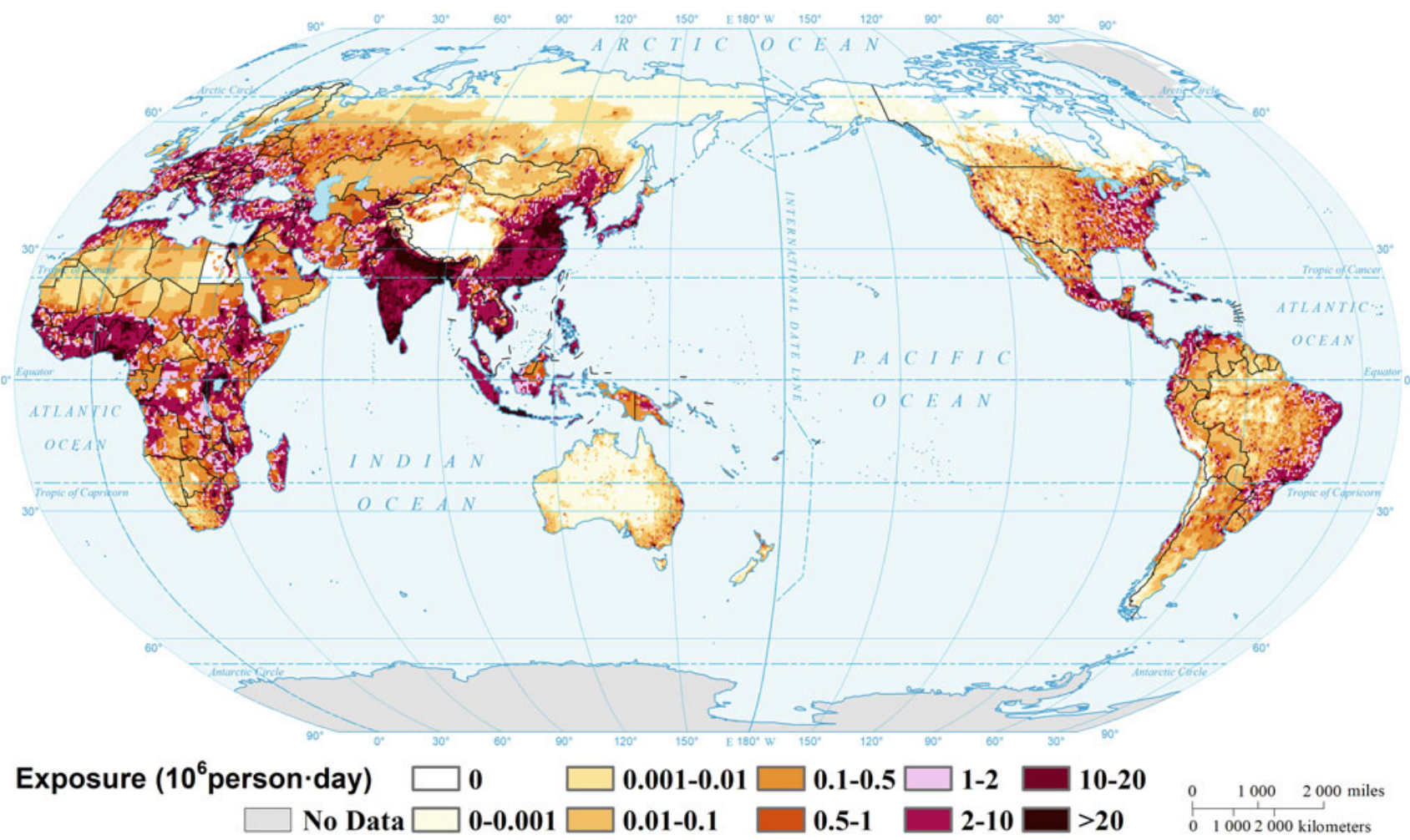


Global population exposure to high temperature (2030s, RCP8.5-SSP3)

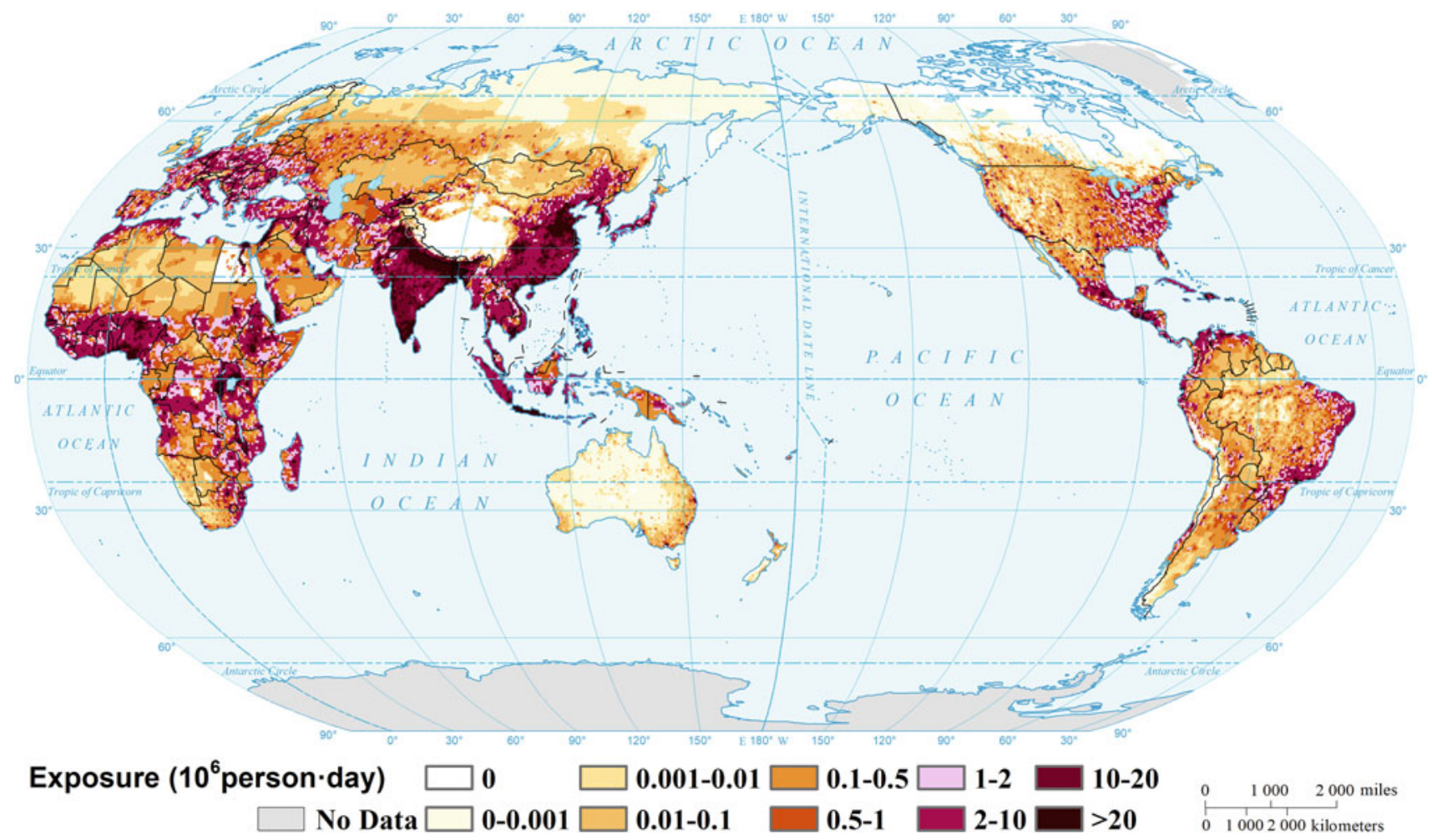

Global population exposure to high temperature (2050s, RCP2.6-SSP1)

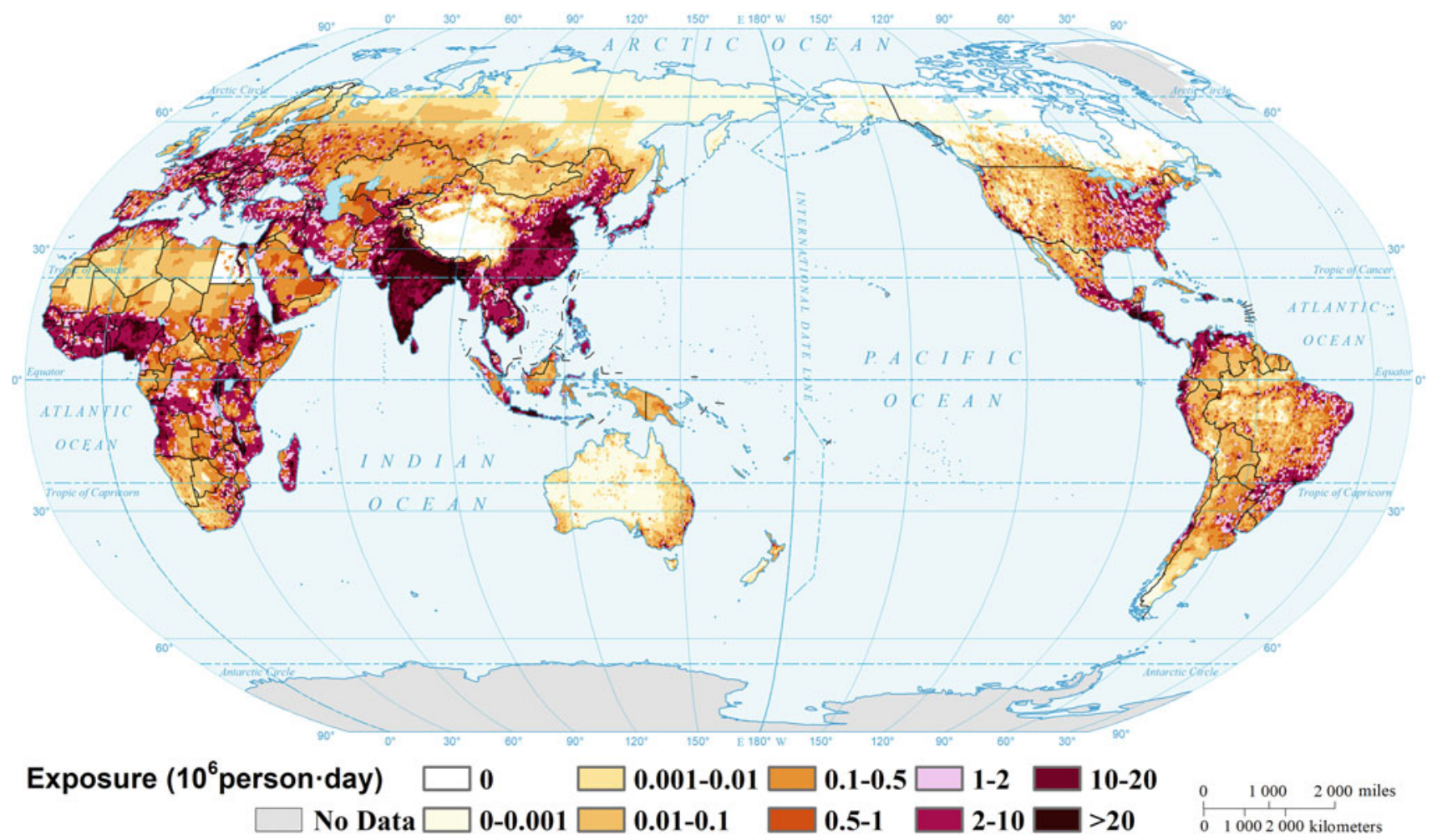


Global population exposure to high temperature (2050s, RCP4.5-SSP2)

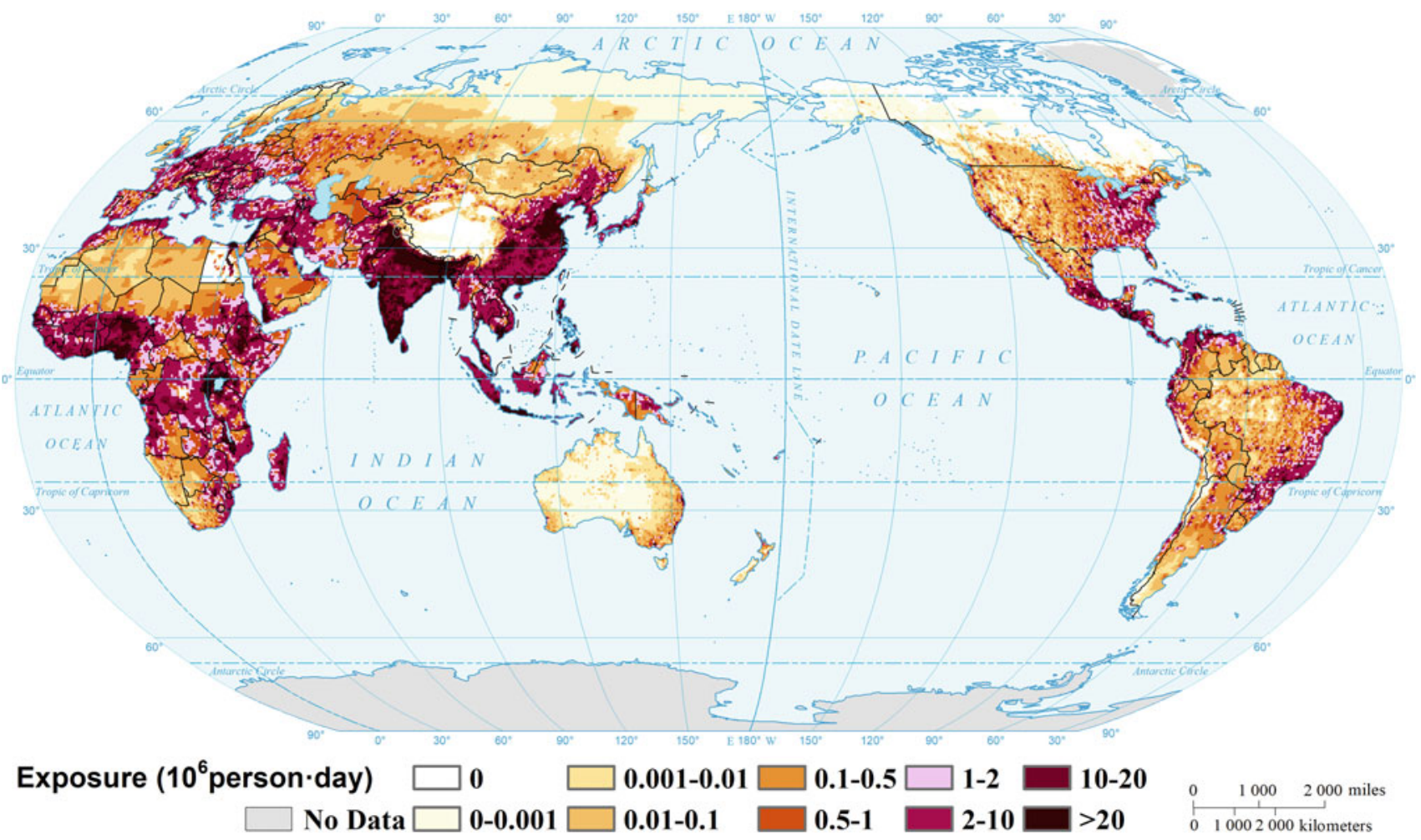

Global population exposure to high temperature (2050s, RCP8.5-SSP3)

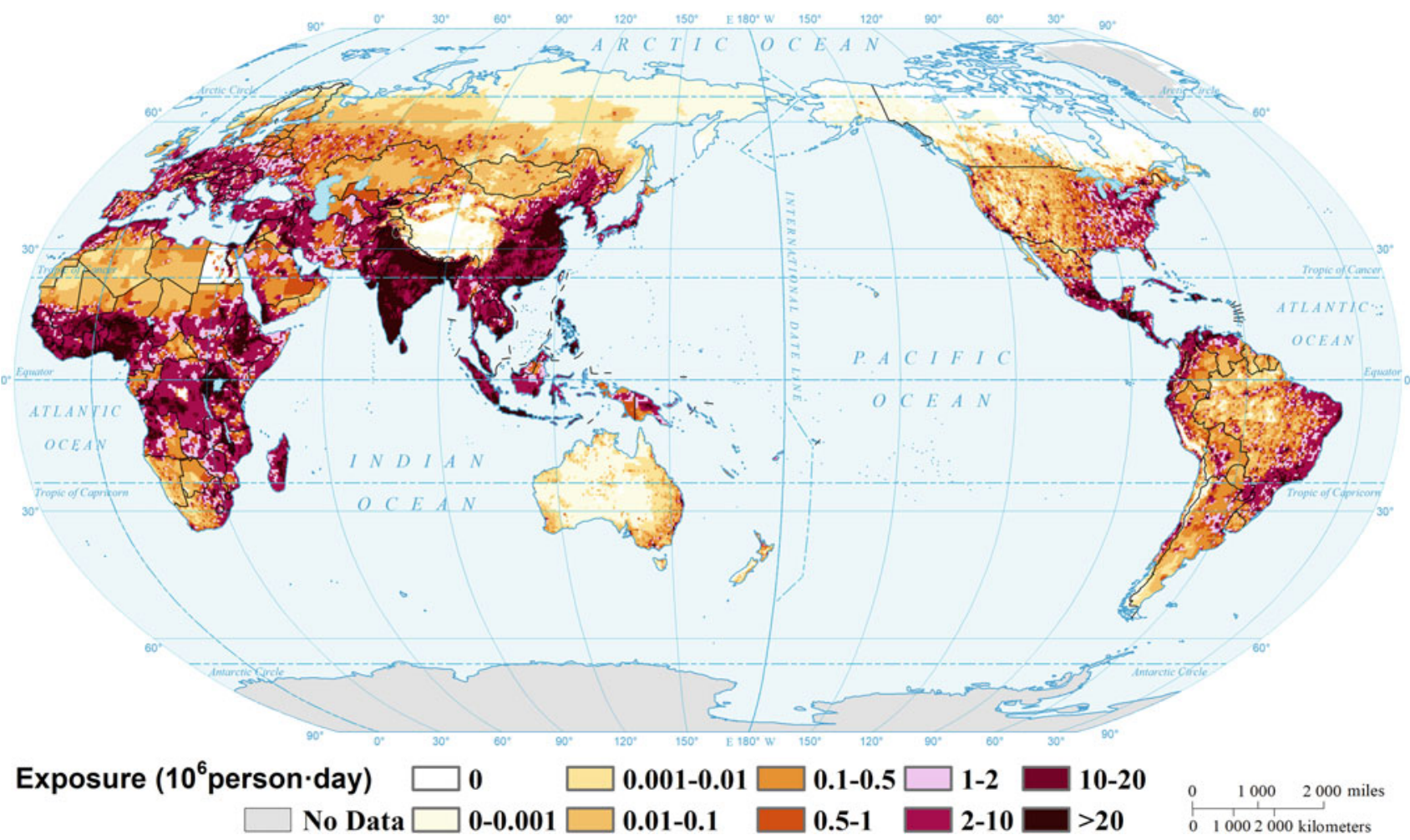




\section{References}

Chen, J., Y.J. Liu, T. Pan, P. Ciais, T. Ma, Y.H. Liu, D. Yamazaki, Q. $\mathrm{Ge}$, et al. 2020. Global socioeconomic exposure of heat extremes under climate change.Journal of Cleaner Production 277. https:// doi.org/10.1016/j.jclepro.2020.123275.

IPCC (Intergovernmental Panel on Climate Change). 2013. Summary for policymakers. In Climate change 2013: The physical science basis. Cambridge, UK: Cambridge University Press.

Jones, B., B.C. O’Neill, L. Mcdaniel, S. Mcginnis, L.O. Mearns, and C. Tebaldi. 2015. Future population exposure to US heat extremes. Nature Climate Change 5: 652-655.

Liu, Z., B. Anderson, K. Yan, W. Dong, H. Liao, and P. Shi. 2017. Global and regional changes in exposure to extreme heat and the relative contributions of climate and population change. Scientific Reports 7: 43909.

Perkins-Kirkpatrick, S.E., and S.C. Lewis. 2020. Increasing trends in regional heatwaves. Nature Communications 11: 1-8.

Robine, J.M., S.L.K. Cheung, S. Le Roy, H. Van Oyen, C. Griffiths, J. P. Michel, and F.R. Herrmann. 2008. Death toll exceeded 70,000 in Europe during the summer of 2003. Comptes Rendus Biologies 331 (2): 171-178.

Seneviratne, S.I., N. Nicholls, D. Easterling, C.M. Goodess, S. Kanae, J. Kossin, Y. Luo, J. Marengo, et al. 2012. Changes in climate extremes and their impacts on the natural physical environment. In Managing the risks of extreme events and disasters to advance climate change adaptation. A special report of the intergovernmental panel on climate change, 9781107025, 109-230. https://doi. org/10.1017/CBO9781139177245.006.
Open Access This chapter is licensed under the terms of the Creative Commons Attribution 4.0 International License (http:// creativecommons.org/licenses/by/4.0/), which permits use, sharing, adaptation, distribution and reproduction in any medium or format, as long as you give appropriate credit to the original author(s) and the source, provide a link to the Creative Commons license and indicate if changes were made.
The images or other third party material in this chapter are included in the chapter's Creative Commons license, unless indicated otherwise in a credit line to the material. If material is not included in the chapter's Creative Commons license and your intended use is not permitted by statutory regulation or exceeds the permitted use, you will need to obtain permission directly from the copyright holder. 